\title{
Mapping Topographic and Vegetation Bioshield Mass Recovery along the Shoreline Using Kite Aerial Photography
}

\author{
Madurapperuma B.D. ${ }^{1,2 *}$, Dellysse J.E. ${ }^{2}$, Kuruppuarachchi \\ K.A.J.M. ${ }^{3}$,DissanayakeG.K.P. ${ }^{4}$ \\ ${ }^{1}$ Department of Forestry \& Wildland Resources, Humboldt State University, USA \\ ${ }^{2}$ Department of Environmental Science \& Management, Humboldt State University, USA \\ ${ }^{3}$ Department of Botany, The Open University of Sri Lanka, Sri Lanka \\ ${ }^{4}$ National Fertilizer Secretariat, Ministry of Agriculture, Sri Lanka \\ *bdm280@humboldt.edu
}

\begin{abstract}
High-resolution aerial photographs coupled with infra-red images are useful for creating terrain models and vegetation mapping. Kite Aerial Photography (KAP) is very reliable for acquiring low altitude aerial images for low-cost and high spatial resolution. This study examined post-tsunami relief in different coastal ecosystems (i.e., mangrove, coastal shrub and sand dune vegetation) in terms of vegetation bioshield mass and sea level rise scenarios. A KAP platform was created using two light-weight automatic cameras with dual bandpass Red-NIR filters, Picavet stabilizing rig, GPS tracker and a Parafoil kite. The high resolution KAP images were processed to build mosaic images, orthorectified and geo-referenced DEMS using structure-from-motion (SfM) and remote sensing software (Agisoft PhotoScan and ENVI respectively). KAP has been utilized for coastal mapping under two scenarios: (i) Normalized Difference Vegetation Index (NDVI) for vegetation bioshield mass estimation (ii) Digital Elevation Model for sea level rise. We produced 1:1500 scale orthorectified maps of coastal habitats representing coastal shrubs, mangroves and sand dune vegetation. The image processing produced a point cloud with an average density of 35 points $/ \mathrm{m}^{2}$; a DEM with 17 $\mathrm{cm}$ resolution; and an orthophoto mosaic with an average resolution of $4.3 \mathrm{~cm}$. The preliminary results of this case study demonstrate the application of KAP for costal habitat vulnerability assessment with an advantage of KAP as low-cost, high spatial/temporal resolution, and limited regulation. In conclusion, KAP has a great potential to bridge science with high spatial/temporal resolution in-situ data for environmental monitoring, where our researchers can utilize the data within a low-cost budget.In the future, comparisons of mapping data from different techniques can be improved with a KAP platform.
\end{abstract}

Keywords: Kite Aerial Photography, Coastal habitat, Keyword, NDVI, Structure-frommotion 